\title{
TWO-WEIGHT INEQUALITIES FOR GEOMETRIC MAXIMAL OPERATORS
}

\author{
ADAM OSȨKOWSKI
}

Abstract. We study one- and two-weight inequalities for the geometric maximal operator on probability spaces equipped with a tree-like structure. We provide a characterization of weights, in terms of Muckenhoupt and Sawyer-type conditions, for which the appropriate strong-type estimates hold. Our approach rests on Bellman function method, which allows us to identify sharp constants involved in the estimates.

Mathematics subject classification (2010): 42B25, 46E30, 60G42.

Keywords and phrases: Maximal, dyadic, Bellman function, best constants.

\section{REFERENCES}

[1] R. BAÑUElos AND A. OsȨKOWSKI, Sharp weak type inequalities for fractional integral operators, Potential Anal. 47 (2017), 103-121.

[2] D. CRUZ-URIBE, The minimal operator and the geometric maximal operator in $\mathbb{R}^{n}$, Studia Math. 144 (2001), no. 1, 1-37.

[3] D. CRUZ-URibe AND C. J. NeUgebauer, Weighted norm inequalities for the geometric maximal operator, Publ. Mat. 42 (1998), 239-263.

[4] C. Fefferman and E. M. Stein, Some maximal inequalities, Amer. J. Math. 93 (1971), pp. 107 115.

[5] A. D. Melas, The Bellman functions of dyadic-like maximal operators and related inequalities, Adv. Math. 192 (2005), 310-340.

[6] F. NAZARov AND S. TReil, The hunt for Bellman function: applications to estimates of singular integral operators and to other classical problems in harmonic analysis, Algebra i Analis 8 (1997), $32-162$.

[7] P. Ortega Salvador and C. Ramírez Torreblanca, Weighted inequalities for the one-sided geometric maximal operators, Math. Nachr. 284 (2011), 1515-1522.

[8] A. OSȨKows KI, Sharp estimates for Lipschitz class, J. Geom. Anal. 26 (2016), 1346-1369.

[9] A. OsȨKOWSKI, Sharp weighted bounds for geometric maximal operators, Glasgow Math. J. 59 (2017), 533-547.

[10] X. SHI, Two inequalities related to geometric mean operators, J. Zhejiang Teacher College 1 (1980), 21-25.

[11] L. Slavin, A. Stokolos And V. Vasyunin, Monge-Ampère equations and Bellman functions: The dyadic maximal operator, C. R. Acad. Sci. Paris, Ser. I 346 (2008), 585-588.

[12] L. SLAVIN AND V. VASYUNIn, Sharp results in the integral-form John-Nirenberg inequality, Trans. Amer. Math. Soc. 363 (2011), 4135-4169.

[13] L. Slavin AND A. Volberg, Bellman function and the $H^{1}-B M O$ duality, Harmonic analysis, partial differential equations, and related topics, 113-126, Contemp. Math., 428, Amer. Math. Soc., Providence, RI, 2007.

[14] V. Vas yunin And A. Volberg, Monge-Ampére equation and Bellman optimization of Carleson embedding theorems, Linear and complex analysis, pp. 195-238, Amer. Math. Soc. Transl. Ser. 2, 226, Amer. Math. Soc., Providence, RI, 2009.

[15] V. VASYUnin AND A. Volberg, Burkholder's function via Monge-Ampére equation, Illinois J. Math. 54 (2010), 1393-1428. 
[16] J. WitTwer, Survey article: a user's guide to Bellman functions, Rocky Mountain J. Math. 41 (2011), $631-661$.

[17] X. YIN AND B. MucKenhoupt, Weighted inequalities for the maximal geometric mean operator, Proc. Amer. Math. Soc. 124 (1996), 75-81. 